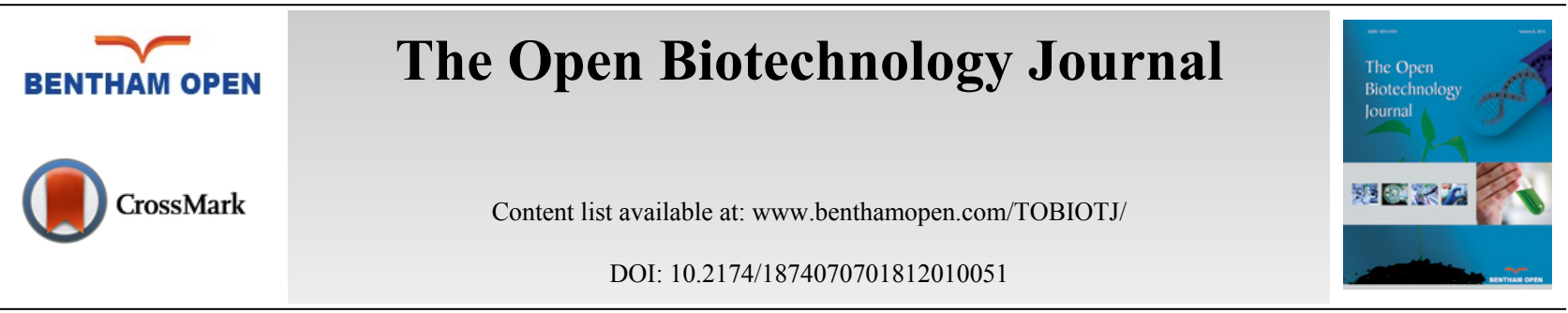

REVIEW ARTICLE

\title{
Feeding World Population Amidst Depleting Phosphate Reserves: The Role of Biotechnological Interventions
}

\author{
S. Antony Ceasar ${ }^{1,2, *}$ \\ ${ }^{I}$ Division of Plant Biotechnology, Entomology Research Institute, Loyola College, Chennai, India \\ ${ }^{2}$ Functional Genomics and Plant Molecular Imaging, Center for Protein Engineering (CIP), Department of Life \\ Sciences, University of Liège, Liège, Belgium
}

Received: February 06, 2018

Revised: April 04, 2018

Accepted: April 09, 2018

\begin{abstract}
Phosphorus (P) is an important macronutrient affecting the growth and yield of all crop plants. Plants absorb P from the soil solution as inorganic phosphate (Pi). More than $70 \%$ of the arable land is deficient of Pi which demands the supply of an external source of synthetic P fertilizers to improve the yields. The P fertilizers are manufactured from non-renewable rock phosphate reserves which are expected to be exhausted within the next 100-200 years. This poses a great threat to food security since it is very difficult to meet the food production caused by increasing world population without the supply of an adequate P fertilizer. Several efforts have been made in the past decade to understand the mechanism of Pi uptake and its redistribution in plants. In this minireview, we discuss the details on possible strategies to combat the crisis caused by loss of phosphate rock reserves and to improve the crop yield without much dependency on external P fertilizer. Approaches such as application of functional genomics studies to manipulate the expression levels of key transcription factors and genes involved in low Pi stress tolerance, molecular marker-assisted breeding to develop new varieties with improved yields under Pi-deficient soils and to recapture the Pi released in wastewaters for recycling back to the farm lands, will help improve the crop production without depending much on non-renewable P fertilizers and will also aid for the sustainable food production.
\end{abstract}

Keywords: Phosphorus, Inorganic phosphate, Phosphorus fertilizer, Phosphate rock, Marker-assisted breeding, Fertilizer.

\section{INTRODUCTION}

We need to improve the food production to feed the ever-growing world population which is projected to reach around 9.7 billion by 2050. Several adverse effects caused by abiotic and biotic stresses like drought, insect damage, fungal diseases and nutrient deficiency are severely affecting crop production throughout the world. Nutrients are essential for the growth and production of all crops in the agriculture system. These are classified into major and minor nutrients based on the amount of nutrients required by plants.

Nutrients are involved in several important cellular functions of the plants. Any lay farmer and gardener working know that plants require three major nutrients viz. nitrogen $(\mathrm{N})$, phosphorus $(\mathrm{P})$ and potassium $(\mathrm{K})$ for their normal growth and yield. Deficiency of all or one of these nutrients severely affects the yield of most of the crop plants throughout the world. Among these three nutrients, N can be easily obtained from the atmosphere; apart from this, simple microbes, through association with legumes, can also fix it. We also have enough resources of K to last for the next several centuries. P plays several vital functions in all living organisms. It participates in several important cellular functions including respiration, photosynthesis, energy conversion, etc. P also participates in the structure of several essential macromolecules like DNA, RNA, ATP and biological membranes. Plants uptake P from the soil in the form of inorganic phosphate $(\mathrm{Pi})$; this process is influenced by soil $\mathrm{pH}$.

\footnotetext{
* Address correspondence to this author at the Division of Plant Biotechnology, Entomology Research Institute, Loyola College, Chennai, India; Tel:+91-44-2817 8348; E-mail: antony_sm2003@yahoo.co.in
} 


\section{PHOSPHATE ROCK RESERVES ARE DEPLETING}

Food production may face severe crisis in the coming decades due to lack of adequate $\mathrm{P}$ fertilizer since $\mathrm{P}$ reserves used for fertilizer production are getting lost rapidly. It has been reported that 5.7 billion hectares of land around the world are Pi-deficient [1]. The deficiency of Pi affects the growth and yield of several crop plants [2]. The phosphate rock, which is the major and non-renewable resource for P fertilizer production, is depleting rapidly. According to estimates, the phosphate rock reserves are expected to be exhausted in the next 200 years or sooner [3, 4]. Further, most of the phosphate rock reserves are located in a few countries like Morocco, USA and Russia leaving behind most of the populated regions in the developing country to depend on heavy import of $\mathrm{P}$ fertilizer. Also, the low input agriculture systems majorly owned by resource-poor and subsistence farmers of less developed countries, especially in Africa and Asia, have little access to $P$ fertilizers due to soaring prices.

Farmers often apply too much P fertilizers to the farmland with a view to improve crop production; however, this application is far beyond the capacity of crop plants to utilize, leading to runoff of $\mathrm{P}$ to the water bodies and causing severe environmental damage [5]. Application of too much $P$ fertilizers also leads to increased storage of $P$ in the seeds [6]. About $60-85 \%$ of the above ground phosphate of cereals is found in the seeds and $75 \%$ of the total phosphorus stored in the seeds is in the form of phytic acid (Phytate) which is an anti-nutrient that is not utilized by the body on consumption [7]. This leads to massive waste of phosphorus.

\section{SOLUTIONS TO COMBAT THE PHOSPHATE CRISIS}

Several efforts have been made by researchers during the past decade to overcome the problems faced by $\mathrm{Pi}$ deficiency and particularly to improve crop production with limited input of non-renewable P fertilizer [8]. Many studies have been conducted to understand the mechanism of Pi uptake and its redistribution in plants, the regulatory mechanism of Pi homeostasis, root architecture modifications under Pi stress and genes and Quantitative Loci (QTLs) responsible for low Pi stress tolerance. These efforts are aimed to improve the low Pi stress tolerance of key crops without compromising the yield. This will help to reduce the dependency on non-sustainable P fertilizers and will promote an eco-friendly farming system. We discuss briefly below the key approaches to achieve this.

\subsection{Functional Genomics Studies to Overcome the Low Pi Stress}

Several key genes involved in the uptake and redistribution of Pi have been identified and characterized in model plants. These include PHosphate Transporter 1 (PHT1) which is the key transporter involved in uptake and disposition of Pi in plants [9] and PHOSPHATE 1(PHO1) which is a Pi exporter involved in the xylem loading of Pi [10]. These two transporters are found to play an important role in Pi uptake, re-distribution and root to shoot transport of Pi; expression levels of these genes also elevated during Pi stress. PHOSPHATE STARVATION RESPONSE 1 (PHR1) is a major Transcription Factor (TF) involved in Pi signalling. It plays a key role in the activation of multiple P-starvationinducible genes including PHT1, PHO1, and microRNA399 (miRNA399) [11, 12]. Manipulation of expression levels of these genes especially PHR1 rescued the plants from low Pi-stress by improving Pi uptake and its re-distribution [13 - 15]. Studies involving the overexpression of these genes especially combined expression of PHT1 and PHO1 will not only help improve the uptake but also will help increase the shoot $\mathrm{P}$ contents under low Pi conditions. Further, tissuespecific manipulation of Pi transporters especially downregulation of those involved in grain filling may also help reduce the seed Pi overloading and will help reduce the phytic acid content in the seeds. To this end, a recent study identified a novel nodal transporter SULTR-like Phosphate Distribution Transporter (SPDT) in rice which is believed to be involved in grain filling of P [16]. Similar studies on other cereals will help to control the excess transfer of P into the seeds. This will assist in reducing the unwanted removal of Pi from the soil and will help retain the soil Pi for the next cropping season. A recent genome editing tool CRISPR/Cas9 may be utilized for more efficient alteration of such transporter genes; this may also help us in circumventing the more stringent rules laid out for GM crops.

\subsection{Marker-Assisted Breeding to Develop Low Pi Stress Tolerant Varieties}

Molecular marker-assisted selection and breeding are powerful tools for selecting and improving the plants for important agronomic traits. Enormous efforts have been made especially during the recent years to identify and develop low Pi stress tolerant varieties in crop plants. Many QTLs have been identified in various crop plants related to low Pstress tolerance which may be useful to improve the P-use efficiency in key crops in the future [17]. QTLs have been identified for key traits of low Pi stress tolerance in many crop plants, including soybean [18], wheat [19], rice [20] and maize [21]. Most of these QTLs are associated with phenotypic modification of root structure to increase the soil 
volume for enhanced Pi uptake under low Pi stress conditions. Although it is a very slow and laborious process, molecular marker-assisted breeding may be helpful to develop new varieties of crop plants including cereals to produce normal yields in Pi-deficient soils. This area of research also offers exploitation of wild relatives to identify more resistant genes which can be transferred to cultivated crops by molecular breeding. These crops will be helpful to improve the yield under Pi stress especially in the regions where GM crops are not permitted like in Europe and most parts of Asia.

\subsection{Removal and Recycling of Pi from Wastewaters}

Pi can be removed and recycled from wastewaters via several different biological methods. These include microbiological, algal, plant-based (terrestrial and aquatic), and combinations of these. Biological methods of Pi removal often provide extra benefits such as the production of bioenergy crops and animal fodder. Previous studies have shown that microalgae viz. Chlorella sp. or Scenedesmus sp. could be used to recapture the Pi from wastewaters $[22,23]$. The Pi capture using these organisms will be possible by the use of waste-water ponds [24] and photobioreactors [25]. Even terrestrial and aquatic higher plants have also been implicated for the removal of Pi and other nutrients [26]. Although these methods seem to be viable for the recapture of Pi from wastewaters, the construction of fully operational pilot plants at all levels of agriculture fields remains a big challenge. Considering the amount of Pi released into the ecosystem from farmland and its consequences, Pi recapture is an essential step to recycle $\mathrm{Pi}$. This will definitely help reduce the dependency on $\mathrm{P}$ fertilizer and will assist in improving the yields in the regions where people cannot afford to buy costly P fertilizers.

\section{CONCLUSION}

The quick depletion of phosphate rock reserves has posed a severe threat to food security. Since it is very difficult to meet food production without the supply of an adequate $\mathrm{P}$ fertilizer, we need to find new ways to improve crop plants for low Pi stress tolerance using functional genomic studies and (or) marker-assisted breeding. New and improved varieties of plants will help produce normal yields under low Pi soil. We also need to take efforts to recapture the Pi from the wastewaters in order to recycle the P back to the farming land. All these efforts will not only help overcome the problems associated with the low Pi soil but will also assist to produce crops in a sustainable manner without much dependency on non-renewable P fertilizers.

\section{CONSENT FOR PUBLICATION}

Not applicable.

\section{CONFLICTS OF INTEREST}

The authors declare no conflict of interest, financial or otherwise.

\section{ACKNOWLEDGEMENTS}

Decleared none.

\section{REFERENCES}

[1] Niu YF, Chai RS, Jin GL, Wang H, Tang CX, Zhang YS. Responses of root architecture development to low phosphorus availability: A review. Ann Bot 2013; 112(2): 391-408. [http://dx.doi.org/10.1093/aob/mcs285] [PMID: 23267006]

[2] Ceasar SA, Hodge A, Baker A, Baldwin SA. Phosphate concentration and arbuscular mycorrhizal colonisation influence the growth, yield and expression of twelve PHT1 family phosphate transporters in foxtail millet (Setaria italica). PLoS One 2014; 9(9): e108459. [http://dx.doi.org/10.1371/journal.pone.0108459] [PMID: 25251671]

[3] Cordell D, Drangert JO, White S. The story of phosphorus: Global food security and food for thought. Glob Environ Change 2009; 19: 292-305.

[http://dx.doi.org/10.1016/j.gloenvcha.2008.10.009]

[4] Sattari SZ, Bouwman AF, Giller KE, van Ittersum MK. Residual soil phosphorus as the missing piece in the global phosphorus crisis puzzle. Proc Natl Acad Sci USA 2012; 109(16): 6348-53. [http://dx.doi.org/10.1073/pnas.1113675109] [PMID: 22431593]

[5] Baker A, Ceasar SA, Palmer AJ, et al. Replace, reuse, recycle: improving the sustainable use of phosphorus by plants. J Exp Bot 2015; 66(12): 3523-40.

[http://dx.doi.org/10.1093/jxb/erv210] [PMID: 25944926] 
[6] Pariasca-Tanaka J, Vandamme E, Mori A, et al. Does reducing seed-P concentrations affect seedling vigor and grain yield of rice? Plant Soil 2015; 392: 253-66. [http://dx.doi.org/10.1007/s11104-015-2460-2]

[7] Raboy V. Approaches and challenges to engineering seed phytate and total phosphorus. Plant Sci 2009; 177: 281-96. [http://dx.doi.org/10.1016/j.plantsci.2009.06.012]

[8] López-Arredondo DL, Leyva-González MA, González-Morales SI, López-Bucio J, Herrera-Estrella L. Phosphate nutrition: Improving lowphosphate tolerance in crops. Annu Rev Plant Biol 2014; 65: 95-123. [http://dx.doi.org/10.1146/annurev-arplant-050213-035949] [PMID: 24579991]

[9] Nussaume L, Kanno S, Javot H, et al. Phosphate Import in Plants: Focus on the PHT1 Transporters. Front Plant Sci 2011 ; 2: 83. [http://dx.doi.org/10.3389/fpls.2011.00083] [PMID: 22645553]

[10] Stefanovic A, Arpat AB, Bligny R, et al. Over-expression of PHO1 in Arabidopsis leaves reveals its role in mediating phosphate efflux. Plant J 2011; 66(4): 689-99. [http://dx.doi.org/10.1111/j.1365-313X.2011.04532.x] [PMID: 21309867]

[11] Rubio V, Linhares F, Solano R, et al. A conserved MYB transcription factor involved in phosphate starvation signaling both in vascular plants and in unicellular algae. Genes Dev 2001; 15(16): 2122-33. [http://dx.doi.org/10.1101/gad.204401] [PMID: 11511543]

[12] Chen J, Liu Y, Ni J, et al. OsPHF1 regulates the plasma membrane localization of low- and high-affinity inorganic phosphate transporters and determines inorganic phosphate uptake and translocation in rice. Plant Physiol 2011; 157(1): 269-78. [http://dx.doi.org/10.1104/pp.111.181669] [PMID: 21753117]

[13] Nilsson L, Müller R, Nielsen TH. Increased expression of the MYB-related transcription factor, PHR1, leads to enhanced phosphate uptake in Arabidopsis thaliana. Plant Cell Environ 2007; 30(12): 1499-512. [http://dx.doi.org/10.1111/j.1365-3040.2007.01734.x] [PMID: 17927693]

[14] Zhou J, Jiao F, Wu Z, et al. OsPHR2 is involved in phosphate-starvation signaling and excessive phosphate accumulation in shoots of plants. Plant Physiol 2008; 146(4): 1673-86. [http://dx.doi.org/10.1104/pp.107.111443] [PMID: 18263782]

[15] Wang X, Bai J, Liu H, Sun Y, Shi X, Ren Z. Overexpression of a Maize Transcription Factor ZmPHR1 Improves Shoot Inorganic Phosphate Content and Growth of Arabidopsis under Low-Phosphate Conditions. Plant Mol Biol Report 2013; 31: 665-77. [http://dx.doi.org/10.1007/s11105-012-0534-3]

[16] Yamaji N, Takemoto Y, Miyaji T, Mitani-Ueno N, Yoshida KT, Ma JF. Reducing phosphorus accumulation in rice grains with an impaired transporter in the node. Nature 2017; 541(7635): 92-5. [http://dx.doi.org/10.1038/nature20610] [PMID: 28002408]

[17] Eshed Y, Zamir D. An introgression line population of Lycopersicon pennellii in the cultivated tomato enables the identification and fine mapping of yield-associated QTL. Genetics 1995; 141(3): 1147-62. [PMID: 8582620]

[18] Liang Q, Cheng X, Mei M, Yan X, Liao H. QTL analysis of root traits as related to phosphorus efficiency in soybean. Ann Bot 2010; 106(1): 223-34. [http://dx.doi.org/10.1093/aob/mcq097] [PMID: 20472699]

[19] Su J-Y, Zheng Q, Li H-W, et al. Detection of QTLs for phosphorus use efficiency in relation to agronomic performance of wheat grown under phosphorus sufficient and limited conditions. Plant Sci 2009; 176: 824-36. [http://dx.doi.org/10.1016/j.plantsci.2009.03.006]

[20] Wang K, Cui K, Liu G, et al. Identification of quantitative trait loci for phosphorus use efficiency traits in rice using a high density SNP map. BMC Genet 2014; 15: 155. [http://dx.doi.org/10.1186/s12863-014-0155-y] [PMID: 25551672]

[21] Chen JY, Xu L, Cai YL, Xu J. Identification of QTLs for phosphorus utilization efficiency in maize (Zea mays L.) across P levels. Euphytica $2009 ; 167$.

[22] Larsdotter K. Microalgae for Phosphorus Removal from Wastewater in a Nordic Climate Royal Institute of Technology, School of Biotechnology. Stockholm: Seden 2006.

[23] Delgadillo-Mirquez L, Lopes F, Taidi B, Pareau D. Nitrogen and phosphate removal from wastewater with a mixed microalgae and bacteria culture. Biotechnol Rep (Amst) 2016; 11: 18-26. [http://dx.doi.org/10.1016/j.btre.2016.04.003] [PMID: 28352536]

[24] Chopin T, Cooper JA, Reid G, Cross S, Moore C. Open-water integrated multi-trophic aquaculture: environmental biomitigation and economic diversification of fed aquaculture by extractive aquaculture. Rev Aquacult 2012; 4: 209-20. [http://dx.doi.org/10.1111/j.1753-5131.2012.01074.x]

[25] Michels MH, Vaskoska M, Vermuë MH, Wijffels RH. Growth of Tetraselmis suecica in a tubular photobioreactor on wastewater from a fish farm. Water Res 2014; 65: 290-6.

[http://dx.doi.org/10.1016/j.watres.2014.07.017] [PMID: 25150516] 
[26] Vermaat JE, Khalid Hanif M. Performance of common duckweed species (Lemnaceae) and the waterfern Azolla filiculoides on different types of waste water. Water Res 1998; 32: 2569-76.

[http://dx.doi.org/10.1016/S0043-1354(98)00037-2]

\section{(C) 2018 S. Antony Ceasar.}

This is an open access article distributed under the terms of the Creative Commons Attribution 4.0 International Public License (CC-BY 4.0), a copy of which is available at: (https:/creativecommons.org/licenses/by/4.0/legalcode). This license permits unrestricted use, distribution, and reproduction in any medium, provided the original author and source are credited. 